\title{
Reported Alcohol Consumption and Cognitive Decline: The Northern Manhattan Study
}

\author{
Clinton B. Wright ${ }^{a}$ Mitchell S.V. Elkind ${ }^{a} \quad$ Xiaodong Luo $^{b}$ Myunghee C. Paik ${ }^{b}$ \\ Ralph L. Sacco ${ }^{\mathrm{a}, \mathrm{c}}$ \\ a Division of Stroke and Critical Care, Department of Neurology, College of Physicians and Surgeons of \\ Columbia University, and Departments of ${ }^{b}$ Biostatistics and ${ }^{c}$ Epidemiology, Mailman School of Public Health, \\ Columbia University, New York, N.Y., USA
}

\section{Key Words}

Alcohol drinking $\cdot$ Cognition disorders · Apolipoprotein E4

\begin{abstract}
Background: Moderate alcohol intake may slow cognitive decline, and both vascular and neurodegenerative mechanisms have been implicated. Methods: We examined reported alcohol intake and cognitive decline in a communitybased cohort of Hispanic, black and white individuals ( $\mathrm{n}=$ 1,428). The role of the apolipoprotein E $\varepsilon 4$ (APOE4) allele as a modifier was also studied. Results and Conclusions: Reported drinking was as follows: 300 participants (21\%) were 'never' drinkers, 622 (44\%) 'past' drinkers, 145 (10\%) reported taking less than 1 drink weekly, 330 (23\%) 1 drink weekly up to 2 daily and 31 (2\%) more than 2 drinks daily. A positive relationship was seen between reported alcohol intake and cognition. Drinking less than 1 drink a week $(p=0.09)$, between 1 drink weekly up to 2 drinks daily ( $p=0.001$ ) and more than 2 drinks daily ( $p=0.003$ ) were associated with less cognitive decline on the modified Telephone Interview for Cognitive Status compared to never drinkers. This dose-response relationship was not modified by the presence of an APOE4 allele in a subsample.

Copyright $\odot 2006$ S. Karger AG, Basel
\end{abstract}

Evidence is accumulating that moderate alcohol consumption may lower the risk of cognitive decline and dementia [1-7]. The benefit may be mediated in part by a protective effect against vascular disease, as moderate alcohol consumption has been shown to lower the risk of stroke as well as subclinical infarcts and white matter disease on brain imaging $[8,9]$. However, moderate alcohol intake has also been found to lower the risk of Alzheimer disease $(\mathrm{AD})$ in two studies $[2,10]$. Few studies have examined the apolipoprotein E $\varepsilon 4$ (APOE4) allele, a strong risk factor for cognitive decline and $\mathrm{AD}$, as a potential mediator of the effect of alcohol on cognition [11]. The results of studies that have been done are mixed, with some reporting that the allele was a modifier and others not finding an association $[5,10,12,13]$.

Alcohol consumption in moderation may provide an opportunity for prevention or delay of cognitive dysfunction if it is found to be protective. To answer this question, data from longitudinal studies using sensitive measures to detect early cognitive changes are needed. Many studies on alcohol intake and cognition to date have been cross-sectional, limiting inferences about causality. Though several longitudinal studies have found that moderate alcohol consumption was associated with less

\section{KARGER}

(c) 2006 S. Karger AG, Basel

Fax +41613061234 E-Mail karger@karger.ch www.karger.com www.karger.com/ned
Clinton Wright, MD, MS

Division of Stroke and Critical Care

College of Physicians and Surgeons of Columbia University

NI-Room 640, 710 W 168th Street, New York, NY 10032 (USA)

Tel. +1 212305 1710, Fax +1 212305 1658, E-Mail cbw7@columbia.edu 
cognitive decline, most have been limited to older subjects $[1,6,14]$ or used less sensitive measures of cognition $[5,7,15]$. Additional data are also needed in diverse populations; most studies have been limited to white subjects, only a few studies have included blacks $[7,16,17]$, and none have included a significant proportion of Hispanic participants. Hispanics are the largest growing segment of the US population, having increased by $58 \%$ in the last decade of the 20th century. Blacks and Hispanics may be at higher risk than whites, since they have higher rates of cerebral small vessel disease and intracranial atherosclerosis and may be at higher risk of dementia and $\operatorname{AD}[18,19]$. The purpose of this study was to measure the effect of alcohol intake on cognitive performance over time in a younger multiethnic community-based sample and to assess the effect of having an APOE4 allele.

\section{Methods}

The Northern Manhattan Study included 3,298 stroke-free participants at baseline identified through random digit dialing using dual-frame sampling as described previously [20]. Community participants were eligible if they had never been diagnosed as having a stroke, were $\geq 40$ years of age ( $>55$ years, beginning 1998) and had been residents of Northern Manhattan for $\geq 3$ months in a household with a telephone. Subjects were recruited from the telephone sample for an in-person assessment, and the overall response rate was $68 \%$. After enrollment, all subjects were followed annually by telephone to determine changes in vital status, detect neurological and cardiac symptoms and events, and note interval hospitalizations. Loss to follow-up from the cohort was less than $1 \%$. The ethics committee of Columbia University Medical Center approved the study, and all subjects signed informed consent.

Data were collected through interviews by trained bilingual research assistants using standardized data collection instruments, review of medical records, physical and neurological examinations by study physicians, and fasting blood samples. Standardized questions about vascular risk factors were adapted from the Centers for Disease Control and Prevention Behavioral Risk Factor Surveillance System as defined previously [21]. Hypertension was defined as a systolic blood pressure $>140 \mathrm{~mm} \mathrm{Hg}$ or a diastolic blood pressure $>90 \mathrm{~mm} \mathrm{Hg}$ based on the mean of 2 blood pressure measurements, self-report of a diagnosis of hypertension or medical treatment thereof. Diabetes was defined as a fasting blood glucose $>127 \mathrm{mg} / \mathrm{dl}$, subject self-report of a diagnosis of diabetes, or insulin or oral hypoglycemic use. Cardiac disease was defined as a history of coronary artery disease, atrial fibrillation or myocardial infarction. Race/ethnicity was based on self-identification, and the distribution at enrollment was approximately $63 \%$ Hispanic, $21 \%$ black, $15 \%$ white and $2 \%$ other groups. Depression was defined as a score on the Hamilton Depression Rating Scale of $>10$ or a history of antidepressant use at time of enrollment or follow-up.

\section{Cognitive Assessment}

The modified Telephone Interview for Cognitive Status (TICS-m) has been administered annually to the prospective cohort since 2001 during telephone follow-up. The original version (TICS) assesses orientation, attention, immediate recall of a 10 word list, calculations, judgment, language, finger tapping and antonyms [22]. The modified version (TICS-m) additionally requires delayed recall of the 10 -word list resulting in a total score of 51 points and has scores that are normally distributed (without ceiling effects) [23]. The TICS-m has good reliability and validity in this multiethnic community [24].

\section{Alcohol Consumption Assessments}

Alcohol use was assessed using structured interviews adapted from food frequency questionnaires as previously described, to create a defined frequency response set $[8,25,26]$. At enrollment, we asked about the average amount consumed in the past year and on average during the participant's drinking lifetime. The followup alcohol assessment at the time of the baseline cognitive examination with the TICS-m asked about intake over the prior 6 months. In both cases, there were 9 possible responses from none to 7 or more drinks per day of wine $(120 \mathrm{ml}$ or $11 \mathrm{~g})$, beer $(360 \mathrm{ml}$ or $12.8 \mathrm{~g}$ ) and liquor ( $45 \mathrm{ml}$ or $14 \mathrm{~g}$ ). The responses for each beverage type were summed to obtain an overall quantity that was divided into categories as described below.

\section{Laboratory Assessments}

Baseline fasting blood samples were drawn into serum tubes and spun within $1 \mathrm{~h}$ at $3,000 \mathrm{~g}$ and $4^{\circ} \mathrm{C}$ for $20 \mathrm{~min}$ and immediately frozen at $-70^{\circ} \mathrm{C}$. High-density lipoprotein cholesterol (HDL-C) levels were measured using an automated spectrometer (Hitachi 705, Boehringer, Mannheim, Germany). The number of APOE 4 alleles carried by each subject was determined by HhaI digestion of PCR products amplified from genomic DNA as described previously [27].

\section{Statistical Analyses}

Statistical analyses were carried out using SAS software (version 8.2, SAS Institute, Cary, N.C., USA). We excluded participants with a history of stroke prior to their first TICS-m and censored scores acquired after strokes. We initially excluded participants with a history of an alcohol-related hospitalization, but also carried out a separate analysis that included these individuals.

As the TICS-m was not instituted in this cohort until 2001, we used the follow-up questions about alcohol intake closest to the first assessment ( $90 \%$ occurred on the same day). We created 5 categories of alcohol intake: (1) never (reference group); (2) past; (3) less than 1 drink weekly; (4) 1 drink weekly up to 2 daily; and (5) more than 2 drinks daily. As noted above, the follow-up questions referred to alcohol intake in the 6 months prior to the interview; however, we took into account their reported consumption at enrollment as well. Patients that reported drinking at enrollment but not at follow-up were considered past drinkers, whereas those that reported no alcohol intake at follow-up were considered never drinkers only if they had been never drinkers at enrollment. Those whose alcohol intake at follow-up differed by 2 categories from enrollment were excluded, to ensure stable drinking patterns over time $(\mathrm{n}=10)$.

We measured the association between reported alcohol intake at the time of the first TICS-m and changes in TICS-m scores over 
time. We employed generalized estimating equations, a multivariate regression method that uses changes of TICS-m scores from the baseline exam as a vector of outcome. An advantage of generalized estimating equations is that even when the covariance structure is unspecified, the correlation among change scores is taken into account. We adjusted for sociodemographic and healthrelated potential confounders associated with cognition or alcohol intake: time between TICS-m administrations, age in years, education, gender, race/ethnicity, health insurance status, HDL-C level, body mass index (BMI), history of hypertension, diabetes, cardiac disease, current smoking, depression and physical inactivity. We tested for interaction in separate models. We also investigated the effect of alcohol on cognition stratified by APOE4 allele status in a subsample of participants for whom these data were available $(\mathrm{n}=600)$.

Not all participants had a complete TICS-m done every year during their telephone follow-up. Differential dropout would be a source of bias only if those that dropped out differed by performance on the TICS-m. To assess for potential bias in the estimates of the relationship between alcohol intake and the outcome of TICS-m change scores, we fitted a logistic regression model using an indicator for those that dropped out after the first TICS-m as the outcome. TICS-m score, reported alcohol intake and the interaction between the two were included in the model along with other relevant covariates.

\section{Results}

Of 3,298 stroke-free participants enrolled between 1993 and 2001, we excluded 31 due to a history of an alcohol-related hospitalization. In addition, 508 died and 80 suffered strokes prior to the initiation of annual cognitive assessment with the TICS-m. Of the 2,631 remaining subjects, 304 died and 48 suffered strokes after the initial TICS-m, leaving 2,279 potentially available for this study. There were 1,428 participants with data on reported alcohol intake and at least 2 TICS-m scores available (mean age 66 years, range 40-98; see table 1 for other characteristics). Compared to those not included in this study, the present sample had more Hispanics (62 vs. $54 \%, \mathrm{p}<0.05$ ), fewer blacks ( 20 vs. $25 \%, \mathrm{p}<0.05)$ and more diabetics $(22$ vs. $19 \%, \mathrm{p}<0.05)$. There was no difference in TICS-m scores or in the interaction between TICS-m scores and alcohol intake comparing those that dropped out after the first TICS-m with those that had complete follow-up assessments.

At the follow-up closest to the baseline TICS-m, 300 participants (21\%) were classified as never drinkers and 622 as past drinkers (44\%). For current drinkers, 145 (10\%) reported drinking less than 1 drink weekly, 330 (23\%) up to 2 drinks daily and 31 (2\%) more than 2 drinks daily. Performance on the TICS-m (mean 31; interquartile range 27-35) differed by drinking category at base- line: past drinkers $(p<0.05)$ and both categories of current drinkers had higher TICS-m scores than never drinkers in univariate analysis $(\mathrm{p}<0.0001)$. Past drinkers had average TICS-m scores 1 point better $($ mean $=30)$, those who drank up to 2 drinks daily 4 points better $($ mean $=33)$ and those who drank more than 2 drinks daily 6 points better (mean 35) than never drinkers $($ mean $=29)$.

Over 6,913 person-years of follow-up (mean 2.2 years, range 0.5-4.4), the mean decline in scores comparing the first to the last TICS-m was 0.4 points (SD 5.6). There was a positive relationship between the amount of reported alcohol intake and performance on the TICS-m over time adjusting for age and educational attainment (table 2, model 1). All 3 categories of current drinkers, but not past drinkers, had significantly less cognitive decline than never drinkers. Adjusting for gender, race/ethnicity and insurance status attenuated the estimates, but the association between current drinking and less decline was still significant (table 2, model 2). After adjusting for vascular risk factors and depression the dose-response relationship remained, although the association between drinking less than 1 drink weekly and cognitive decline remained only a trend. However, taking more than 1 drink weekly was still associated with less cognitive decline in the fully adjusted model (table 2, model 3). In a sensitivity analysis we included those with a history of an alcohol-related hospitalization $(n=31)$, and the protective effect against cognitive decline in those reporting more than 2 drinks daily was attenuated somewhat, but remained significant.

There was no significant difference in baseline TICS-m scores between APOE4 allele carriers (mean $31.5, \mathrm{SD} 6.8, \mathrm{n}=155$ ) and noncarriers (mean 32.1, SD 6.4, $\mathrm{n}=445$ ). In addition, the change over time did not differ significantly between carriers and noncarriers $(\mathrm{p}=0.1)$. The effect of alcohol intake on cognitive performance was not modified by APOE4 allele status.

\section{Conclusions}

In this stroke-free community-based cohort we found that current drinkers had less cognitive decline on a telephone cognitive assessment than never drinkers, adjusting for sociodemographic and vascular risk factors. In addition, there was no interaction by APOE4 status on the beneficial effect of alcohol intake on cognitive function. This study has several strengths including the prospective design, allowing for measurement of cognitive 
Table 1. Characteristics of study sample by reported alcohol intake

\begin{tabular}{|c|c|c|c|c|c|c|}
\hline \multirow[t]{2}{*}{ Variable } & \multirow{2}{*}{$\begin{array}{l}\text { Overall, \% } \\
\mathrm{n}=1,428\end{array}$} & \multicolumn{5}{|c|}{ Reported drinking behavior at baseline TICS-m } \\
\hline & & $\begin{array}{l}\text { Never } \\
\mathrm{n}=300\end{array}$ & $\begin{array}{l}\text { Past } \\
\mathrm{n}=622\end{array}$ & $\begin{array}{l}\text { 1/month - } \\
<1 / \text { week } \\
\mathrm{n}=145\end{array}$ & $\begin{array}{l}\text { 1/week - } \\
2 / \text { day } \\
n=330\end{array}$ & $\begin{array}{c}>2 / \text { day }^{*} \\
\mathrm{n}=31\end{array}$ \\
\hline Mean age $\pm S D$, years & $71 \pm 9$ & $72 \pm 9^{*}$ & $71 \pm 9$ & $68 \pm 9$ & $69 \pm 9$ & $68 \pm 7$ \\
\hline Women, $\%$ & 67 & $28^{*}$ & 44 & 9 & 18 & $<1$ \\
\hline \multicolumn{7}{|l|}{ Education, \% } \\
\hline$<8$ years & 42 & $30^{*}$ & 48 & 8 & 13 & 1 \\
\hline$>8$ and $<12$ years & 13 & 19 & 42 & 12 & 26 & $<1$ \\
\hline High school graduate & 16 & 16 & 45 & 11 & 24 & 3 \\
\hline Some college & 12 & 17 & 39 & 11 & 30 & 3 \\
\hline Graduate degree & 17 & 9 & 34 & 13 & 40 & 4 \\
\hline \multicolumn{7}{|l|}{ Insurance status, \% } \\
\hline None & 12 & $23^{*}$ & 48 & 8 & 19 & 2 \\
\hline Medicaid & 45 & 27 & 47 & 8 & 16 & 2 \\
\hline Private & 43 & 14 & 39 & 13 & 31 & 3 \\
\hline \multicolumn{7}{|l|}{ Race/ethnicity, \% } \\
\hline Hispanic & 62 & $25^{*}$ & 46 & 9 & 18 & 2 \\
\hline Black & 19 & 16 & 44 & 11 & 27 & 2 \\
\hline White & 19 & 11 & 35 & 13 & 37 & 4 \\
\hline Hypertension, \% & 82 & $23^{*}$ & 45 & 9 & 21 & 2 \\
\hline Diabetes, \% & 25 & $26^{*}$ & 47 & 10 & 17 & $<1$ \\
\hline Cardiac disease, $\%$ & 19 & 21 & 45 & 9 & 24 & 1 \\
\hline Current smokers, \% & 13 & $11^{*}$ & 44 & 9 & 32 & 4 \\
\hline \multicolumn{7}{|l|}{$\mathrm{BMI}^{*}, \%$} \\
\hline$>30$ & 30 & $20^{*}$ & 41 & 11 & 26 & 2 \\
\hline $25-30$ & 43 & 18 & 44 & 11 & 24 & 3 \\
\hline$<25$ & 27 & 20 & 41 & 11 & 26 & 2 \\
\hline Depression, \% & 3 & $21^{*}$ & 49 & 6 & 23 & 0 \\
\hline Any physical activity, \% & 59 & $21^{*}$ & 39 & 11 & 27 & 2 \\
\hline Mean total homocysteine $\pm S D$ & $9.9 \pm 3.0$ & $9.2 \pm 2.7$ & & $9.9 \pm 7.5^{* *}$ & $9.0 \pm 3.1$ & $10.7 \pm 4.2^{* *}$ \\
\hline Mean HDL-C \pm SD & $47 \pm 14$ & $47 \pm 13$ & $46 \pm 14$ & $46 \pm 14$ & $48 \pm 15$ & $47 \pm 16$ \\
\hline Mean TICS-m \pm SD & $31 \pm 6$ & $29 \pm 6$ & & $30 \pm 6$ & $33 \pm 6^{* *}$ & $35 \pm 6^{* *}$ \\
\hline
\end{tabular}

decline. Also, our multiethnic urban population includes Hispanics and blacks at greater risk of dementia than their white counterparts [28].

Our findings are in agreement with other recent prospective studies showing that alcohol intake may decrease the risk of cognitive decline $[1,13,29]$. One prospective study found no effect, but they used the Mini Mental State Exam, which lacks sensitivity [14]. Some studies have found a graded association between reported alcohol intake and cognition [30-32], although Ushaped relationships have also been found $[33,34]$. Other prospective studies have found a benefit for those who consumed less than 1 drink a day or an equal benefit among all categories of intake $[1,13]$. We found a doseresponse effect against cognitive decline for those that reported current drinking. There was no difference in cognitive decline between past drinkers and never drinkers, but the former is a heterogeneous group that includes a wide range of both past alcohol intake and time since becoming abstinent. Therefore, we felt it was important to keep them separate. Participants that reported drinking more than 2 drinks daily showed incrementally less cognitive decline than never drinkers. Given that the heavier drinking group was small $(\mathrm{n}=31)$ and the poten- 
Table 2. Relation between reported alcohol intake and performance on repeated measures of TICS-m

\begin{tabular}{|c|c|c|c|c|c|c|c|c|c|}
\hline \multirow[t]{2}{*}{ Model } & \multirow[t]{2}{*}{ Never } & \multicolumn{2}{|l|}{ Past } & \multicolumn{2}{|c|}{$\begin{array}{l}1 \mathrm{drink} / \text { month to } \\
<1 \mathrm{drink} / \text { week }\end{array}$} & \multicolumn{2}{|c|}{$\begin{array}{l}1 \text { drink/week up to } \\
2 \text { drinks/day }\end{array}$} & \multicolumn{2}{|l|}{$>2$ drinks/day } \\
\hline & & $\beta$ & $\mathrm{p}$ & $\beta$ & $\mathrm{p}$ & $\beta$ & $\mathrm{p}$ & $\beta$ & $\mathrm{p}$ \\
\hline Model 1 & ref. & $0.6(-0.2,1.3)$ & 0.14 & $1.5(0.5,2.5)$ & 0.003 & $2.2(1.3,3.0)$ & $<0.0001$ & $2.9(1.4,4.4)$ & 0.0002 \\
\hline Model 2 & ref. & $0.3(-0.4,1.1)$ & 0.40 & $1.0(0.03,1.9)$ & 0.04 & $1.6(0.7,2.4)$ & 0.0003 & $2.1(0.6,3.6)$ & 0.008 \\
\hline Model 3 & ref. & $0.4(-0.4,1.2)$ & 0.36 & $0.9(-1.2,1.9)$ & 0.09 & $1.5(0.6,2.4)$ & 0.001 & $2.4(0.8,4.0)$ & 0.003 \\
\hline
\end{tabular}

The $\beta$ coefficient represents the change in points on the TICS-m over time compared to never drinkers; positive denotes better scores. The figures in parentheses represent 95\% confidence limits. Model $1=$ Adjusted for age and education; model $2=$ model $1+$ gender, race/ethnicity and insurance status; model $3=$ model $2+$ history of hypertension, diabetes, cardiac disease, physical inactivity, depression, current smoking, HDL-C level and BMI.

tial harm of excessive alcohol intake considerable, larger studies are needed to clarify the effects of this level of alcohol intake on cognition. In this study $70 \%$ of those in the highest category drank less than or equal to 4 drinks daily $(\mathrm{n}=22$ of 31 ). Thus, most were not very heavy drinkers.

We did not find a difference at baseline or over time in TICS-m scores between APOE4 carriers and noncarriers. The results of other studies have been mixed, with 2 studies showing a benefit of alcohol intake in APOE4 noncarriers in relation to cognitive decline and dementia, respectively $[5,10]$. In the National Heart, Lung and Blood Institute twin study, only drinkers that were APOE4 carriers appeared to benefit. Interestingly, the Nurses' Health Study also used the TICS-m, as well as other tests, and likewise found APOE4 status had no effect. One possible explanation of our findings is that the smaller sample size combined with the relatively short mean follow-up (2.2 years) may have limited our ability to detect differences between the groups in this smaller sample. The mechanism by which alcohol might mediate the effect of APOE4 on cognition is not clear. However, APOE4 is known to be less effective at membrane repair and as an antioxidant than other isoforms [35]. Given that APOE4 binds $\beta$-amyloid and is involved in its deposition in the plaques of $\mathrm{AD}$, alcohol may decrease oxidation and deposition of $\beta$ amyloid in the brains of those at risk [36]. Separately, evidence from animal studies suggests alcohol may increase brain acetylcholine [37]. Since this neurotransmitter is depleted in $\mathrm{AD}$, alcohol could improve cognition in those affected even in the early stages.

Many if not most cases of dementia may be due to AD with vascular disease. In such cases, alcohol may have a benefit through its effects on the vascular system. We find it of note that adjusting for vascular risk factors had little effect on the change in TICS-m scores. Thus, alcohol may act on the vascular system independently of other risk factors. Moderate alcohol consumption appears to be protective against stroke and subclinical cerebrovascular disease, which may explain part of any beneficial effect of moderate alcohol consumption on cognition $[8,9]$. In a cross-sectional study we did not find carotid plaque to be a mediator of this relationship [38]. However, in the Cardiovascular Health Study moderate alcohol consumption was associated with less subclinical brain disease [9]. Thus, microangiopathy may be more relevant, and additional studies are needed to clarify the importance of small vessel disease in this relationship. One potential mechanism is through raising HDL-C levels [39]. In this study, HDL-C levels did not differ significantly by alcohol category and were not associated with cognitive performance in multivariate analysis. Moderate alcohol consumption also has inhibitory effects on platelet aggregation, degranulation and formation of thromboxane $\mathrm{A}_{2}$ [40]. We did not systematically gather information on nonsteroidal anti-inflammatory drug use, although we did ask about aspirin use. Excluding aspirin users in a post hoc analysis had no effect on our results (data not shown).

This study has several limitations. In this and other studies involving self-reported alcohol use and cognition, current drinkers may be healthier than nondrinkers. This may be because the latter have stopped drinking due to health problems or because they lack social or other attributes possessed by the drinkers. Such bias is minimized by examining changes in scores. Also, factors in our cohort known to be associated with lower socioeconomic status such as having Medicaid, no insurance, or 
being Hispanic or black compared to white were more common among nondrinkers, which would tend to minimize our findings. Another potential source of bias is differential dropout from the repeated TICS-m assessments that is dependent on alcohol intake. However, we found that dropouts did not differ by TICS-m score or the interaction between TICS-m and alcohol intake. Another limitation is our reliance on cognitive assessment done over the telephone. While the TICS-m may not be as valid as in-person neuropsychological testing, scores on the TICS-m correlate well with in-person testing in a somewhat healthier sample of 323 Northern Manhattan Study participants that have received both. In addition, the TICS- $m$ has been found to be sensitive in detecting mild cognitive impairment in other studies [41].

In this longitudinal study of cognitive performance, we found that current drinkers suffered less decline on a cognitive test compared to never drinkers. This effect was not modified by APOE4 allele status. A larger sample of heavier drinkers is needed to clarify the dose of alcohol that may protect against cognitive decline without causing damage. Future studies in a larger sample from this cohort may clarify this and race/ethnic differences in drinking patterns and cognitive performance. In addition, brain imaging studies will help determine the relative importance of subclinical vascular disease in the causal pathway between alcohol consumption and cognition.

\section{Acknowledgment}

This work is supported by grants from the National Institutes of Health (5 K12 RR176548-02), the National Institute of Neurological Disorders and Stroke (R01 NS 29993) and the Irving General Clinical Research Center (2 M01 RR00645). We would like to thank the staff of the Northern Manhattan Study, in particular Janet DeRosa, project manager.

\section{References}

1 Espeland MA, Gu L, Masaki KH, Langer RD, Coker LH, Stefanick ML, Ockene J, Rapp SR: Association between reported alcohol intake and cognition: results from the Women's Health Initiative Memory Study. Am J Epidemiol 2005;161:228-238.

$\checkmark 2$ Orgogozo JM, Dartigues JF, Lafont S, Letenneur L, Commenges D, Salamon R, Renaud $S$, Breteler MB: Wine consumption and dementia in the elderly: a prospective community study in the Bordeaux area. Rev Neurol 1997;153:185-192.

- 3 Huang W, Qiu C, Winblad B, Fratiglioni L: Alcohol consumption and incidence of dementia in a community sample aged 75 years and older. J Clin Epidemiol 2002;55:959964.

-4 Mukamal KJ, Kuller LH, Fitzpatrick AL, Longstreth WT Jr, Mittleman MA, Siscovick DS: Prospective study of alcohol consumption and risk of dementia in older adults. JAMA 2003;289:1405-1413.

$\checkmark 5$ Dufouil C, Tzourio C, Brayne C, Berr C, Amouyel P, Alperovitch A: Influence of apolipoprotein $\mathrm{E}$ genotype on the risk of cognitive deterioration in moderate drinkers and smokers. Epidemiology 2000;11:280-284.

-6 Herbert LE, Scherr PA, Beckett LA, Albert MS, Rosner B, Taylor JO, Evans DA: Relation of smoking and low-to-moderate alcohol consumption to change in cognitive function: a longitudinal study in a defined community of older persons. Am J Epidemiol 1993;137:881-891. reroi I, Sheppard JM, Lyketsos CG: Cognitive function after 11.5 years of alcohol use: relation to alcohol use. Am J Epidemiol 2002; 156:747-752.

-8 Sacco RL, Elkind M, Boden-Albala B, Lin IF, Kargman DE, Hauser WA, Shea S, Paik MC: The protective effect of moderate alcohol consumption on ischemic stroke. JAMA 1999;281:53-60.

-9 Mukamal KJ, Longstreth WT Jr, Mittleman MA, Crum RM, Siscovick DS: Alcohol consumption and subclinical findings on magnetic resonance imaging of the brain in older adults: the cardiovascular health study. Stroke 2001;32:1939-1946.

10 Luchsinger JA, Tang MX, Siddiqui M, Shea S, Mayeux R: Alcohol intake and risk of dementia. J Am Geriat Soc 2004;52:540-546.

-11 Blair CK, Folsom AR, Knopman DS, Bray MS, Mosley TH, Boerwinkle E: Atherosclerosis Risk in Communities Study I: APOE genotype and cognitive decline in a middleaged cohort. Neurology 2005;64:268-276.

12 Carmelli D, Swan GE, Reed T, Schellenberg GD, Christian JC: The effect of apolipoprotein $\mathrm{E} \varepsilon 4$ in the relationships of smoking and drinking to cognitive function. Neuroepidemiology 1999;18:125-133.

-13 Stampfer MJ, Kang JH, Chen J, Cherry R, Grodstein F: Effects of moderate alcohol consumption on cognitive function in women. N Engl J Med 2005;352:245-253.

14 Launer LJ, Feskens EJ, Kalmijn S, Kromhout D: Smoking, drinking, and thinking: the Zutphen Elderly Study. Am J Epidemiol 1996;143:219-227.
15 Andersen K, Launer LJ, Dewey ME, Letenneur L, Ott A, Copeland JR, Dartigues JF, Kragh-Sorensen P, Baldereschi M, Brayne C, Lobo A, Martinez-Lage JM, Stijnen T, Hofman A, EURODEM Incidence Research Group: Gender differences in the incidence of $\mathrm{AD}$ and vascular dementia: the EURODEM Studies. Neurology 1999;53:19921997.

16 Hendrie HC, Gao S, Hall KS, Hui SL, Unverzagt FW: The relationship between alcohol consumption, cognitive performance, and daily functioning in an urban sample of older black Americans. J Am Geriatr Soc 1996; 44:1158-1165.

17 Cerhan JR, Folsom AR, Mortimer JA, Shahar E, Knopman DS, McGovern PG, Hays MA, Crum LD, Heiss G, Atherosclerosis Risk in Communities (ARIC) Study Investigators: Correlates of cognitive function in middleaged adults. Gerontology 1998;44:95-105.

18 Sacco RL, Kargman DE, Gu Q, Zamanillo MC: Race-ethnicity and determinants of intracranial atherosclerotic cerebral infarction: the Northern Manhattan Stroke Study. Stroke 1995;26:14-20.

19 Tang MX, Cross P, Andrews H, Jacobs DM, Small S, Bell K, Merchant C, Lantigua R, Costa R, Stern Y, Mayeux R: Incidence of AD in African-Americans, Caribbean Hispanics, and Caucasians in northern Manhattan. Neurology 2001;56:49-56. 
-20 Elkind MS, Cheng J, Boden-Albala B, Paik MC, Sacco RL, The Northern Manhattan Stroke Study: Elevated white blood cell count and carotid plaque thickness: The Northern Manhattan Stroke Study. Stroke 2001;32: 842-849.

21 Sacco RL, Benson RT, Kargman DE, BodenAlbala B, Tuck C, Lin IF, Cheng JF, Paik MC, Shea S, Berglund L: High-density lipoprotein cholesterol and ischemic stroke in the elderly: the Northern Manhattan Stroke Study JAMA 2001;285:2729-2735.

22 Brandt J, Spencer M, Folstein MF: The Telephone Interview For Cognitive Status. Neuropsychiatry Neuropsychol Behav Neurol 1988;1:111-117.

$\checkmark 23$ De Jager CA, Budge MM, Clarke R, Barak Y, Aizenberg D, Achiron A: Utility of TICS-M for the assessment of cognitive function in older adults. Int J Geriatr Psychiatry 2003; 18:318-324.

-24 Desmond D, Tatemichi TK, Hanzawa L: The Telephone Interview For Cognitive Status (TICS): reliability and validity in a stroke sample. Int J Geriatr Pshychiatry 1994:803807.

-25 Block G, Hartman AM, Dresser CM, Carroll MD, Gannon J, Gardner L: A data-based approach to diet questionnaire design and testing. Am J Epidemiol 1986;124:453-469.

-26 Willett WC, Sampson L, Stampfer MJ, Rosner B, Bain C, Witschi J, Hennekens $\mathrm{CH}$, Speizer FE: Reproducibility and validity of a semiquantitative food frequency questionnaire. Am J Epidemiol 1985; 122:51-65.

27 Hixson JE, Vernier DT: Restriction isotyping of human apolipoprotein $\mathrm{E}$ by gene amplification and cleavage with HhaI. J Lipid Res 1990;31:545-548.
28 Gurland BJ, Wilder DE, Lantigua R, Stern Y, Chen J, Killeffer EH, Mayeux R: Rates of dementia in three ethnoracial groups. Internat J Geriatr Psychiatry 1999;14:481-493.

29 Bond GE, Burr R, McCurry SM, Rice MM Borenstein AR, Kukull WA, Teri L, Bowen JD, McCormick WC, Larson EB: Alcohol, gender, and cognitive performance: a longitudinal study comparing older Japanese and non-Hispanic white Americans. J Aging Health 2004;16:615-640.

30 Dufouil C, Ducimetiere P, Alperovitch A, Epidemiology of Vascular Aging (EVA) Study Group: Sex differences in the association between alcohol consumption and cognitive performance. Am J Epidemiol 1997; 146:405-412.

31 Kalmijn S, van Boxtel MP, Verschuren MW, Jolles J, Launer LJ: Cigarette smoking and alcohol consumption in relation to cognitive performance in middle age. Am J Epidemiol 2002;156:936-944.

32 Elias PK, Elias MF, D’Agostino RB, Silbershatz H, Wolf PA: Alcohol consumption and cognitive performance in the Framingham Heart Study. Am J Epidemiol 1999;150:580 589.

33 Galanis DJ, Joseph C, Masaki KH, Petrovitch H, Ross GW, White L: A longitudinal study of drinking and cognitive performance in elderly Japanese American men: the Honolulu-Asia Aging Study. Am J Public Health 2000;90:1254-1259.
34 Christian JC, Reed T, Carmelli D, Page WF, Norton JA Jr, Breitner JC: Self-reported alcohol intake and cognition in aging twins. J Stud Alcohol 1995;56:414-416.

35 Lanterna LA, Rigoldi M, Tredici G, Biroli F, Cesana C, Gaini SM, Dalpra L: APOE influences vasospasm and cognition of noncomatose patients with subarachnoid hemorrhage. Neurology 2005;64:1238-1244.

36 Ruitenberg A, van Swieten JC, Witteman JC, Mehta KM, van Duijn CM, Hofman A, Breteler MM: Alcohol consumption and risk of dementia: the Rotterdam Study. Lancet 2002; 359:281-286.

>37 Henn C, Loffelholz K, Klein J: Stimulatory and inhibitory effects of ethanol on hippocampal acetylcholine release. Naunyn Schmiedebergs Arch Pharmacol 1998;357: 640-647.

38 Wright CB, Elkind MS, Rundek T, BodenAlbala B, Paik MC, Sacco RL: Alcohol intake, carotid plaque, and cognition: the Northern Manhattan Study. Stroke 2006;37: 1160-1164.

39 Gaziano JM, Buring JE, Breslow JL, Goldhaber SZ, Rosner B, VanDenburgh M, Willett W, Hennekens $\mathrm{CH}$ : Moderate alcohol intake, increased levels of high-density lipoprotein and its subfractions, and decreased risk of myocardial infarction. N Engl J Med 1993;329:1829-1834.

40 Rubin R, Rand ML: Alcohol and platelet function. Alcohol Clin Exp Res 1994;18:105110.

-41 Lines CR, McCarroll KA, Lipton RB, Block GA, Prevention of Alzheimer's in Society's Elderly Study Group: telephone screening for amnestic mild cognitive impairment. Neurology 2003;60:261-266. 